\title{
Biomass burning as a source of dissolved iron to the open ocean?
}

\author{
Cécile Guieu, Sophie Bonnet, and Thibaut Wagener \\ Laboratoire d'Océanographie de Villefranche, Villefranche-Sur-Mer, France
}

Marie-Dominique Loÿe-Pilot

Plateforme Environnement, Ecole Normale Supérieure, Paris, France

Received 11 March 2005; revised 30 August 2005; accepted 6 September 2005; published 14 October 2005.

[1] While the Mediterranean region is typified by frequent summer fires, the 2003 heat wave that hit Europe, and France in particular, made this season longer causing devastating fires. Aerosol sampling performed in the French Riviera between August and September 2003 indicated that iron concentrations in 2003 were significantly higher than in previous years. Continuous pyrogenic emissions are suspected to be the cause of high $\mathrm{Fe}$ concentrations. When these particles were dissolved in seawater, $2 \%$ of the total iron content was found in solution. This amount could be significant for the water column on a regional scale. Indeed, these fires might explain the observed dissolved iron enrichment of the surface mixed layer $(+0.4 \mathrm{nM})$ measured in the Ligurian Sea during August. In contrast to a locally significant effect, pyrogenic inputs have little impact on the global Fe budget since they represent at most $10 \%$ of desert dust inputs. Citation: Guieu, C., S. Bonnet, T. Wagener, and M.-D. Loÿe-Pilot (2005), Biomass burning as a source of dissolved iron to the open ocean?, Geophys. Res. Lett., 32, L19608, doi:10.1029/2005GL022962.

\section{Introduction}

[2] The iron cycle in the Mediterranean Sea is strongly influenced by atmospheric inputs to the water column. There are two major reasons for the sensitivity to the atmospheric input. First, the close vicinity of continental sources, especially the Saharan desert, provides a source for considerable amounts of iron-rich dust. Secondly, the heavy stratification of the surface water column during a large part of the year, which dramatically reduces exchange between surface and deep waters, allows the accumulation of the atmospheric input to the surface mixed layer.

[3] According to Sarthou and Jeandel [2001], after the spring bloom of phytoplankton, and in the absence of any Saharan dust input, the surface mixed layer can become Fedepleted, with concentrations lower than $0.1 \mathrm{nM}$. Bonnet et al. [2005] conducted incubation experiments in August 2003 to assess if, under such conditions, low iron concentrations in the surface mixed layer may limit primary production, or at least control phytoplankton species composition. The seawater needed for these microcosm experiments was collected at the beginning of August 2003. Surprisingly, although almost no Saharan input has been recorded since the beginning of stratification, water in the surface mixed layer was found to be significantly enriched in dissolved iron relative to underlying waters.

Copyright 2005 by the American Geophysical Union. 0094-8276/05/2005GL022962
[4] This paper examines, using simultaneously collected atmospheric and ocean data, the different hypotheses that could explain this enrichment. In particular, the role played by emissions from the significant amount of biomass that burned in the Mediterranean area during the long heat wave that hit Europe in summer 2003 is investigated.

\section{Materials and Methods}

2.1. Seawater Collection and Analysis of Dissolved Iron

[5] Seawater was collected at 10 meters on the 1 st of August 2003 in the Ligurian Sea at the JGOFS-DYFAMED site (Figure 1). The stratification was clear with a thermocline at 14 meters depth. Iron concentrations were measured on shore using flow injection analysis with chemiluminescence detection (detailed description of the sampling, analysis and blanks is given by Bonnet et al. [2005]).

\subsection{Aerosol Sampling and Analysis of Total Particulate Iron}

[6] Aerosol sampling was performed at the Cap Ferrat site (altitude $138 \mathrm{~m}$ ), a signal station located on a peninsula close to the town of Nice (Figure 1). This site is exposed to both natural and anthropogenic inputs [Migon et al., 2002]. Two acid-cleaned polycarbonate filter holders were placed upside down (to avoid the impact of rain drops) at 3 meters above the ground. Air was filtered through a Nuclepore ${ }^{\circledR}$ polycarbonate membrane with a pore size of $0.4 \mu \mathrm{m}$. The flow rate was $1.3 \mathrm{~m}^{3} \cdot \mathrm{h}^{-1}$ during collection, and the air volumes filtered were on average $16 \mathrm{~m}^{3}$. At the end of sampling, filters were stored inside clean petri slides. In addition, a particle counter was placed close to the filterholders in order to identify the grain size distribution of aerosols collected on the filters.

[7] Between August 21, 2003 and September 6, 2003, ten aerosol samples were collected, analyzed for total iron, and used to perform dissolution experiments. Aerosol samples were $\mathrm{HNO}_{3} / \mathrm{HF}$ acid-digested inside a microwave oven using suprapur reagents. GBW reference material (NRCC) was digested following the same protocols as used with the samples to test the reliability of the method. Reagent blanks and filter blanks were included as control for possible contamination during the process. Fe was analyzed in digested samples by ICP-AES and concentrations determined using calibration graphs. Blanks (reagents alone and reagents + blank filter) were below the detection limit. Percent recovery obtained with the certified reference material was $\mathrm{Fe}=101 \% \pm 2 \%$, indicating a quantitative and accurate digestion and analysis. $\mathrm{K}$ and $\mathrm{Na}$ were analyzed by flame-AAS. 


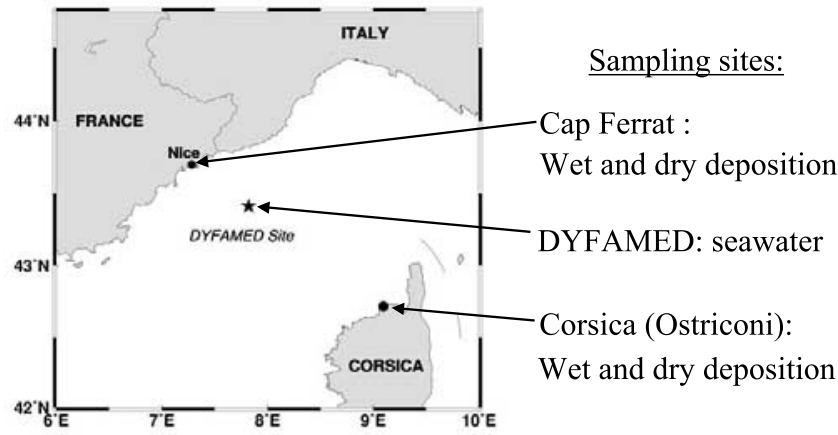

Figure 1. Location of atmosphere and seawater sampling sites.

\subsection{Aerosol Dissolution Experiment}

[8] The second filter was added to $200 \mathrm{ml}$ of $0.2 \mu \mathrm{m}$ filtered seawater (same seawater as used by Bonnet and Guieu [2004]) in an opaque Teflon flask. As described by Bonnet and Guieu [2004], the flasks were left undisturbed, except for a gentle, twice-a-day shake for 7 days. This was assumed to be representative of the contact time between the atmospheric particles and seawater in such a highly stratified system. On day 7 , the seawater was filtered through an acid-cleaned Nuclepore polycarbonate membrane (pore size $0.2 \mu \mathrm{m}$ ) and acidified to $\mathrm{pH} 2$ with $\mathrm{HCl}$. Total dissolved iron was measured using flow injection analysis with chemiluminescence detection (see section 2.1).

\section{Results}

\subsection{Aerosol Concentrations and Particle Size Distribution}

[9] The iron concentration of the aerosol samples ranged between 0.209 to $0.509 \mu \mathrm{g} . \mathrm{m}^{-3}$ with an average concentration of $0.350 \mu \mathrm{g} . \mathrm{m}^{-3}$ (Figure 2). These concentrations were quite stable during the period sampled (variation of coefficient $=25 \%$ ). The particle size distribution in number was identical for all samples: on average 90 percent of the particles were in the size range $0.3-0.5 \mu \mathrm{m}, 5$ percent were in the size range $0.5-0.7 \mu \mathrm{m}$ and only $\sim 2 \%$ were $>0.7 \mu \mathrm{m}$. The aerosol size distribution in smoke plumes is character-
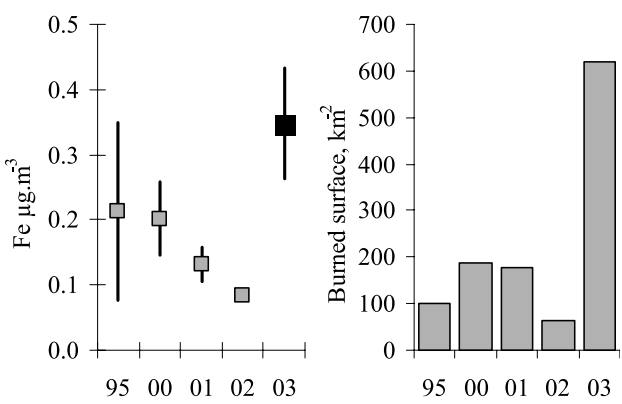

Figure 2. (left) Iron concentration in aerosol collected at the Cap Ferrat Station in summer: 2003 (this study) compared with 1995 [Journel, 1998], 2000, 2001 and 2002 [Michelon, 2003]. (right) Surfaces burnt in the French Mediterranean regions for the studied years. ized by two mass modes: one around $0.3 \mu \mathrm{m}$ and the other in the supermicron size range [Le Canut et al., 1996]. When considering the volume particle size distribution, our data show that over $50 \%$ of the particles collected had diameter $>1 \mu \mathrm{m}$. This is due to the close proximity of the fires and the size increase of the pyrogenic particles by aging. Thus, it seems reasonable to consider that these particles have a deposition velocity on the order of $1 \mathrm{~cm} \cdot \mathrm{s}^{-1}$, in close agreement with the velocity $\left(1-2 \mathrm{~cm} \cdot \mathrm{s}^{-1}\right)$ actually measured for forest fire aerosols by Kashparov et al. [2000].

\subsection{Solubility of Burning-Period-Aerosol Iron in Seawater}

[10] During dissolution $\sim 0.6$ to $2 \%$ of iron associated with the sampled aerosols was found to dissolve in seawater. We have shown previously that the dissolution is highly dependent upon the amount of atmospheric particles introduced during a dissolution experiment [Guieu et al., 2002a; Bonnet and Guieu, 2004]. As we do not know the mass of collected aerosols, the dissolution rates obtained here are represented as a function of the total iron concentration resulting from the introduction of the particles to seawater (Figure 3). Figure 3 also includes results from Bonnet and Guieu [2004] for iron dissolution from typical Saharan dust and anthropogenic dust. These prior experiments were designed to mimic actual atmospheric input, taking into account the dilution of atmospheric particles in the mixed layer. For example, for a Saharan event of medium intensity, a final dust concentration in the mixed layer of $0.1 \mathrm{mg} .1^{-1}$ was assumed. Since the dust used by Bonnet and Guieu [2004] had a total iron concentration of $5 \%$, this is equivalent to a total iron concentration of $90 \mathrm{nM}$ in Figure 3. In the present experiment, the particle load was much higher than the actual input to the mixed layer. Additionally, these particles contained much less iron than Saharan dust (see section 4.5 ). Thus $2 \%$ iron dissolution is a reasonable value for 'natural' conditions.

\section{Discussion}

\subsection{Evidence of a Dissolved Iron Enrichment in the Surface Mixed Layer}

[11] In August 2003, we found that the concentration of $\mathrm{Fe}$ in the mixed surface layer was $0.9 \mathrm{nM}$, indicating an

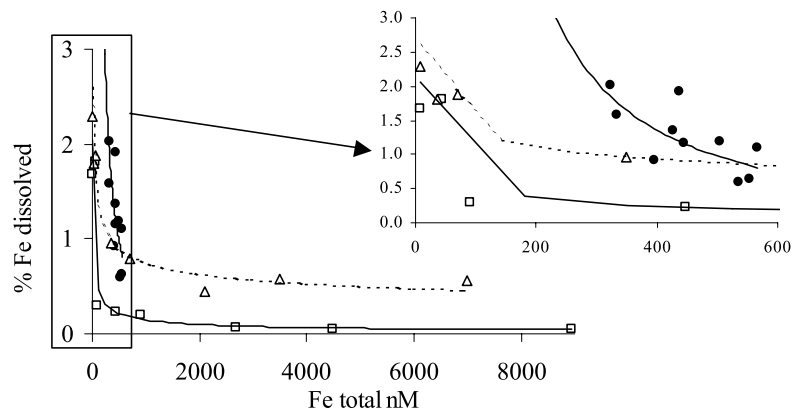

Figure 3. Dissolution of iron from aerosols collected during summer '03 (dots). The X-axis represents the iron concentration that would be obtained upon $100 \%$ dissolution of Fe. Data for Saharan (squares) and anthropogenic (triangles) particles from Bonnet and Guieu [2004]. 
enrichment of $0.4 \mathrm{nM} \mathrm{Fe}$ with respect to underlying waters. Despite the limited number of studies concerning the iron cycle in the open Mediterranean Sea, most of the data concern the DYFAMED site. Sarthou and Jeandel [2001] found an increase in surface water dissolved iron, and they hypothesized that, during this period of water column stratification in this area (June-October), the strong stratification and the low surface production may allow atmospheric (dissolved) iron to accumulate in the surface mixed layer. Guieu et al. [2002b] found that the surface water enrichment measured in October 1998 was attributed to the numerous Saharan inputs that occurred during the oligotrophic season. Estimation made from direct measurement of the atmospheric deposition was in strong agreement with the observed dissolved iron accumulation $(0.8 \mathrm{nM})$ and supports the atmospheric origin from Sahara of the iron enrichment observed at this time. In contrast, after the spring bloom of phytoplankton, and in the absence of any Saharan dust input, the surface mixed layer can become Fedepleted, with concentrations less than $0.1 \mathrm{nM}$ [Sarthou and Jeandel, 2001]. Interestingly, each of these studies consistently showed that, below the thermocline, concentrations remain constant up to $150 \mathrm{~m}$ and are of the order of $0.50 \mathrm{nM}$.

\subsection{Saharan Dust Did Not Cause the Enrichment}

[12] In 2003, after the beginning of the stratification, only small inputs from Saharan dust were recorded on both sides of the Ligurian Sea. One rain event at Cap Ferrat accounted for a dust flux of $0.288 \mathrm{~g} . \mathrm{m}^{-2}$, and three, small rain events recorded in Corsica accounted for a total dust flux of $0.310 \mathrm{~g} . \mathrm{m}^{-2}$. These fluxes are of the same order of magnitude and we can assume that the flux in the Ligurian Sea was not higher than measurements on both sides of it. We also expect that the main dissolution of iron from these particles occurred in seawater because dust deposition was associated with almost no rainfall. By applying an aerosol Fe dissolution percentage $(0.4 \%)$ (established by Bonnet and Guieu [2004] for the corresponding dust concentration in seawater), and considering that the total iron concentration in Saharan dust is $4.5 \%$ [Guieu et al., 2002b], we calculated that a flux of at most $\sim 0.300$ g.m ${ }^{-2}$ of dust would have increased the dissolved concentration in the surface mixed layer by $0.06 \mathrm{nM}$, which is only $15 \%$ of the observed enrichment.

\subsection{Evidence of Higher Iron Aerosol Concentration in Summer 2003}

[13] The iron concentration of the aerosols samples collected during summer 2003 were compared with concentrations measured at the Cap Ferrat site during the same period but for previous years (Figure 2). 1995 and 2000 were influenced by high Saharan inputs and have a high mean Fe concentration; the other years were less influenced by Saharan events and reflect more the "usual" local background (mainly "polluted") and show lower Fe mean concentrations. The data clearly indicate that, in summer 2003, the iron concentration was higher (average of 0.350 $\mu \mathrm{g} . \mathrm{m}^{-3}$ ) when compared to an average for the previous years' data of $0.190 \mu \mathrm{g} . \mathrm{m}^{-3}$. While the Mediterranean region is typified by frequent summer fires, the 2003 heat wave that hit Europe, and France in particular, made this season longer, causing devastating fires. High temperatures stoked forest fires from Poland to the Iberian Peninsula, with blazes so extensive that they were easily observed by satellite (e.g., MODIS TERRA, http://modis.gsfc.nasa. gov/). The fires in southern France and Corsica started at the beginning of July and lasted 2.5 months, destroying $\sim 620 \mathrm{~km}^{2}$ just within the French coast of the Ligurian Sea (http://www.promethee.com). Compared to previous years for which aerosol concentrations are available (Figure 2, right), the burned surface in the French Mediterranean region was higher by at least a factor of three. The highest iron aerosol concentrations coincide with this increase of burned biomass. Our aerosols were collected while burning was occurring relatively close to the sampling site, and we strongly suspect that this is the cause of the observed high concentrations. It is expected that the usual background of anthropogenic pollutant and suspended soil particles contributed to our signal, but were small in comparison to the pyrogenic contribution. It is well known that non-sea salt $\mathrm{K}$ ( ${ }_{\mathrm{NSS}} \mathrm{K}$ ) is a good indicator of burned biomass [Andreae, 1983], not only in terms of elemental concentration, but also by normalizing it relative to other elemental concentrations such as Al [see Ruellan et al., 1999, and references therein]. $\mathrm{Al}$ was not measured in our samples, and we compared our ${ }_{\mathrm{NSS}} \mathrm{K} / \mathrm{Fe}$ ratio to different end-member ratios ( ${ }_{\mathrm{NSS}} \mathrm{K}$ was estimated from $\mathrm{Na}$, considering that $\mathrm{Na}$ in the aerosol was entirely of marine origin). Except for one sample with particularly high ${ }_{\mathrm{NSS}} \mathrm{K} / \mathrm{Fe}$ ratio of 1.8 , the ratio obtained during our study was $0.63 \pm 0.12$ : this is higher than the ratio for polluted aerosols (0.27: Urban particulate matter standard reference \#1648, NIST) and for crustal aerosols (0.49 in continental crust [Wedepohl, 1995]), confirming that $\mathrm{K}$ primarily originates from fire.

\subsection{Potential Impact on Seawater [Fe] in the Ligurian Sea}

[14] To our knowledge, very little data exists on iron concentrations in aerosols emitted by fires [Maenhaut et al., 1996, Reid et al., 1998]. In a more specific study devoted to the determination of the photochemically available $\mathrm{Fe}$ in ambient aerosols, Siefert et al. [1996] considered aerosols emitted under different environmental conditions, including strong fires. For a series of samples collected close to a fire, they showed a high increase in total Fe concentrations associated with high amounts of suspended particles resulting from the combustion of biomass and the suspension of dust and soil particles. From a series of samples collected on a site at a distance of $100 \mathrm{~km}$ from a fire, they found a threefold increase in $\mathrm{Fe}_{\text {total }}$ compared to the concentration in marine air masses, having a Fe concentration of $0.316 \pm$ $23 \mu \mathrm{g} . \mathrm{m}^{-3}$. This is very similar to the mean concentration of our aerosol during the 2003 summer $\left(0.350 \mu \mathrm{g} \cdot \mathrm{m}^{-3}\right)$.

[15] We can use data collected in this and previous studies to check the hypothesis that the observed enrichment in the mixed layer was related to pyrogenic emissions: iron concentration $=0.350 \mu \mathrm{g} \cdot \mathrm{m}^{-3} ; 2 \%$ of the iron content of these particles can be dissolved in seawater; these particles have a deposition velocity of $1-2 \mathrm{~cm} . \mathrm{s}^{-1}$. The duration of the emission before the seawater sampling was 30 days (fires started at the beginning of July in the Mediterranean Region). We have assumed that the particle flux and the dissolution from the particles affects the whole mixed layer, whose depth was $12 \mathrm{~m}$ in July and $15 \mathrm{~m}$ in august. 
Table 1. Atmospheric Input of Iron at the Global Scale: Respective Contribution of Pyrogenic and Desert Sources

\begin{tabular}{|c|c|c|}
\hline & Pyrogenic Source & Desert Source \\
\hline $\begin{array}{l}\text { Total particles flux } \\
\text { Fe: Flux total } \\
\text { Fe: Dissolved flux }\end{array}$ & $\begin{array}{l}104 \times 10^{12} \mathrm{~g}^{\mathrm{gyr}}{ }^{-1}[\text { Andreae, } 1991] \\
0.416 \times 10^{12} \mathrm{~g}^{-y^{-1 a}} \\
8.3 \times 10^{9} \text { g.yr }{ }^{-1 b}\end{array}$ & $\begin{array}{l}14 \times 10^{12} \mathrm{~g}^{\mathrm{yr}} \mathrm{yr}^{-1}[\text { Gao et al., 2001] } \\
112 \times 10^{9} \mathrm{~g}_{\mathrm{yr}}^{-1 \mathrm{c}}\end{array}$ \\
\hline
\end{tabular}

${ }^{\mathrm{a}} \mathrm{Fe}$ content in such particles $=0.4 \%$ [Harden et al., 2004].

${ }^{\mathrm{b}}$ Dissolution $=2 \%$ (this study).

${ }^{\mathrm{c}}$ Assuming a dissolution of $0.8 \%$ [Bonnet and Guieu, 2004]

[16] Given the above assumption, we expect that an increase of 0.22 to $0.45 \mathrm{nM}$ of dissolved iron in the entire mixed layer could have resulted from the deposition of these aerosols that were influenced by the fires. The $0.4 \mathrm{nM}$ enrichment measured in the Central Ligurian Sea likely included a minor contribution from Saharan dust, a very small contribution of the "usual" polluted background and a main fraction due to aerosols emitted by fires. In addition to the Fe concentration in the usual background aerosol, $\mathrm{Fe}$ content of such pyrogenic aerosols may have included Fe content of the plants themselves and a lithogenic fraction that was entrained at the time of the fires. A number of assumptions were made in this calculation. In particular, the deposition velocity is a poorly constrained factor. Also, the percentage of dissolution could be higher for a more realistic particle concentration. Since our data support that the impact on $[\mathrm{Fe}]$ is high compared to other sources, we can conclude that, at the regional and seasonal scale, biomass burning is a significant source of dissolved iron for the surface seawater. Furthermore, as pointed out by Beniston [2004], heat waves like the one recently experienced in Europe may become more common as climate responds to enhanced atmospheric greenhouse gases. Among other consequences we may expect a stronger impact to the marine system from pyrogenic emissions on a regional scale.

\subsection{Potential Impact at the Global Scale}

[17] Recent discussions of the global iron cycle have typically focused on eolian input as the most significant source [Parekh et al., 2004]. Given our original results, it is reasonable to compare the contributions of desert and pyrogenic iron sources globally (Table 1).

[18] The total particle flux from burned biomass is estimated to be $104 \times 10^{12} \mathrm{~g} \mathrm{yr}^{-1}$ [Andreae, 1991]. The Fe content of such particles is not very well constrained, and we considered here the recent quantity of $0.4 \%$ of iron in burned ash/char in boreal forest fire [Harden et al., 2004]. This concentration is in agreement with statistics from Reid et al. [1998]: $0.2-0.8 \%$ in smoke hazes in Brazil. Considering that $2 \%$ of iron attached to these aerosols will dissolve in seawater (this study), this calculation gives a soluble iron flux originating from the pyrogenic source of $8.3 \times$ $10^{9} \mathrm{~g}_{\mathrm{gr}}{ }^{-1}$. Taking into account that the data used in this calculation are quite imprecise, this number should only be considered as order of magnitude.

[19] Nevertheless, using the total iron flux emitted from desert sources [Gao et al., 2001] and applying a percentage of dissolution of iron of $0.8 \%$ [Bonnet and Guieu, 2004], we conclude that the input from pyrolitic source represents less than $10 \%$ of the desert source. The pyrogenic fluxes were considered at the global scale, and this percentage thus should be even lower when considering only the inputs to the surface of the ocean. Our results indicate that pyrogenic aerosols have little impact on the global marine iron cycle.

\section{References}

Andreae, M. O. (1983), Soot carbon and excess fine potassium: Long-range transport of combustion-derived aerosols, Science, 220, 1148-1151.

Andreae, M. O. (1991), Biomass burning: Its history, use, and distribution and its impact on environmental quality and global climate, in Global Biomass Burning: Atmospheric, Climatic and Biospheric Implications, edited by J. S. Levine, pp. 3-21, MIT Press, Cambridge, Mass.

Beniston, M. (2004), The 2003 heat wave in Europe: A shape of things to come? An analysis based on Swiss climatological data and model simulations, Geophys. Res. Lett., 31, L02202, doi:10.1029/ 2003 GL018857.

Bonnet, S., and C. Guieu (2004), Dissolution of atmospheric iron in seawater, Geophys. Res. Lett., 31(3), L03303, doi:10.1029/2003GL018423.

Bonnet, S., C. Guieu, J. Chiaverini, J. Ras, and A. Stock (2005), Effect of atmospheric nutrients on the autotrophic communities in a low nutrient, low chlorophyll system, Limnol. Oceanogr., in press.

Gao, Y., Y. J. Kaufman, D. Tanre, D. Kolber, and P. G. Falkowski (2001), Seasonal distributions of aeolian iron fluxes to the global ocean, Geophys. Res. Lett., 28, 29-32.

Guieu, C., Y. Bozec, S. Blain, C. Ridame, G. Sarthou, and N. Leblond (2002a), Impact of high Saharan dust inputs on dissolved iron concentrations in the Mediterranean Sea, Geophys. Res. Lett., 29(19), 1911, doi:10.1029/2001GL014454.

Guieu, C., M.-D. Loÿe-Pilot, C. Ridame, and C. Thomas (2002b), Chemical characterization of the Saharan dust end-member; some biological implications for the western Mediterranean, J. Geophys. Res., 107(D15), 4258, doi:10.1029/2001JD000582.

Harden, J. W., J. C. Neff, D. V. Sandberg, M. R. Turetsky, R. Ottmar, G. Gleixner, T. L. Fries, and K. L. Manies (2004), Chemistry of burning the forest floor during the FROSTFIRE experimental burn, interior Alaska, 1999, Global Biogeochem. Cycles, 18(3), GB3014, doi:10.1029/2003GB002194.

Journel, B. (1998), Apports atmosphériques de métaux en Mer Ligure: Caractérisation géochimique et devenir dans la colonne d'eau (site DYFAMED), Ph.D., 347 pp., Univ. Aix-Marseille, Marseille, France.

Kashparov, V. A., S. M. Lundin, A. M. Kadygrib, V. P. Protsak, S. E. Levtchuk, V. I. Yoschenko, V. A. Kashpur, and N. M. Talerko (2000), Forest fires in the territory contaminated as a result of the Chernobyl accident: Radioactive aerosol resuspension and exposure of fire-fighters, J. Environ. Radioact., 51, 281-298.

Le Canut, P. L., M. O. Andreae, G. W. Harris, F. G. Wienhold, and T. Zenker (1996), Airborne studies of emissions from savanna fires in southern Africa: 1. Aerosol emissions measured with a laser optical particle counter, J. Geophys. Res., 101, 23,615-23,630.

Maenhaut, W., I. Salma, J. Cafmeyer, H. J. Annegarn, and M. O. Andreae (1996), Regional atmospheric aerosol composition and sources in the eastern Transvaal, South Africa, and impact of biomass burning, J. Geophys., Res., 101, 23,631-23,650.

Michelon, S. (2003), Suivi des apports atmosphériques en sels nutritifs en milieu côtier ouest méditerranéen, M. S. diss., Univ. ParisVII-ParisXII, Paris.

Migon, C., V. Sandroni, J. C. Marty, B. Gasser, and J. C. Miquel (2002), Transfer of atmospheric matter through the euphotic layer in the northwestern Mediterranean: Seasonal pattern and driving forces, Deep Sea Res., Part II, 49, 2125-2142.

Parekh, P., M. J. Follows, and E. Boyle (2004), Modeling the global ocean iron cycle, Global Biogeochem. Cycles, 18, GB1002, doi:10.1029/ 2003 GB002061.

Reid, J. S., P. V. Hobbs, R. J. Ferek, D. R. Blake, J. V. Martins, M. R. Dunlap, and C. Liousse (1998), Physical, chemical, and optical properties of regional hazes dominated by smoke in Brazil, J. Geophys. Res., 103, $32,059-32,080$. 
Ruellan, S., H. Cachier, A. Gaudichet, P. Masclet, and J. P. Lacaux (1999) Airborne aerosols over central Africa during the Experiment for Regional Sources and Sinks of Oxidants (EXPRESSO), J. Geophys. Res., 104 30,673-30,690

Sarthou, G., and C. Jeandel (2001), Seasonal variations of iron concentrations in the Ligurian Sea and iron budget in the western Mediterranean Sea, Mar. Chem., 74, 115-129.

Siefert, R. L., S. Webb, and M. R. Hoffmann (1996), Determination of photochemically available iron in ambient aerosols, J. Geophys. Res., $101,14,441-14,449$.
Wedepohl, K. H. (1995), The composition of the continental crust, Geochim. Cosmochim. Acta, 59, 1217-1232.

S. Bonnet, C. Guieu, and T. Wagener, Laboratoire d'Océanographie de Villefranche, UMR 7093, BP 28, F-06234 Villefranche-sur-Mer Cedex, France. (guieu@obs-vlfr.fr)

M.-D. Loÿe-Pilot, Plateforme Environnement, Ecole Normale Supérieure, 45 rue d'Ulm, F-75230 Paris Cedex 05, France. 